\title{
Application of conditional probability analysis to distant metastases from lung cancer
}

\author{
AKIHIRO OIKAWA $^{1}$, HIDETO TAKAHASHI ${ }^{2}$, HIROICHI ISHIKAWA ${ }^{3}$, \\ KOICHI KURISHIMA ${ }^{4}$, KATSUNORI KAGOHASHI ${ }^{5}$ and HIROAKI SATOH ${ }^{5}$ \\ ${ }^{1}$ Master's Program in Medical Sciences, University of Tsukuba; ${ }^{2}$ Department of Epidemiology and Biostatistics, \\ School of Medicine, University of Tsukuba; ${ }^{3}$ Division of Respiratory Medicine, Tsukuba Medical Center; \\ ${ }^{4}$ Division of Respiratory Medicine, Institute of Clinical Medicine, University of Tsukuba; \\ ${ }^{5}$ Division of Respiratory Medicine, Mito Medical Center, University of Tsukuba, Ibaraki 310-0015, Japan
}

Received October 5, 2011; Accepted December 19, 2011

DOI: $10.3892 / \mathrm{ol} .2011 .535$

\begin{abstract}
The aim of this study was to reveal whether there was non-randomness in the occurrence of metastasis and, if the nonrandomness was denied, whether there were specific metastatic patterns in lung cancer patients. Patients who presented with pathologically diagnosed lung cancer between January 1986 and March 2009 at our hospitals were included. A statistical method and conditional probability analysis were used to analyze the data. Under the condition of one metastatic organ A (lung, bone, brain, liver or adrenal gland; the 5 most common metastatic organs), we determined the conditional probability of distant metastasis to a specific organ $\mathrm{B}$, which was written as $\mathrm{P}(\mathrm{B} \mid \mathrm{A})$, and compared it with the probability of distant metastasis $\mathrm{P}(\mathrm{B})$. The study group consisted of 1,994 patients. Of the 1,994 patients, $839(42.1 \%)$ had distant metastases at the time of the initial diagnosis of lung cancer. With the exception of the comparisons between $\mathrm{P}$ (lung) and $\mathrm{P}$ (lung |adrenal gland) and between $\mathrm{P}$ (adrenal gland) and $\mathrm{P}$ (adrenal gland $\mid$ lung), there were statistically significant differences between $\mathrm{P}(\mathrm{B} \mid \mathrm{A})$ and $\mathrm{P}(\mathrm{B})$ in the 5 metastatic organs. In addition, $\mathrm{P}(\mathrm{B} \mid \mathrm{A})$ and $\mathrm{P}(\mathrm{C}|\mathrm{B}| \mathrm{A})$ varied according to each organ and $\mathrm{P}$ (confined to $\mathrm{A})$, $\mathrm{P}$ (confined to $\mathrm{A}$ and $\mathrm{B}$ ) and $\mathrm{P}($ confined to $\mathrm{A}, \mathrm{B}$ and $\mathrm{C})$ were different in each metastatic organ. In lung cancer patients, distant metastasis occurred non-randomly and there may be certain specific patterns of distant metastasis. The accumulation of knowledge of specific patterns of metastasis may aid the approach to individualized treatments.
\end{abstract}

\section{Introduction}

In patients with lung cancer, distant metastatic disease is generally considered a contra-indication to resection of the

Correspondence to: Dr Hiroaki Satoh, Division of Respiratory Medicine, Mito Medical Center, University of Tsukuba, Mito, Ibaraki 310-0015, Japan

E-mail: hirosato@md.tsukuba.ac.jp

Key words: conditional probability, metastases, lung cancer, statistics, non-randomness, metastatic patterns primary tumor (1). Knowledge of the sites of metastatic disease and the frequency with which metastasis occurs at presentation may be used to design appropriate algorithms for the pretreatment imaging work-up and to provide the most suitable treatment. Previously, there was a large-scale study of the metastatic patterns of adenocarcinoma cases, but the study dealt only with autopsy records (2). Previous studies on autopsied patients have led to several dominant conflicting theories to explain the distribution of metastases (3-5). The mechanical theory, proposed by Ewing, states that the distribution of tumor metastases is explained entirely on the basis of blood flow patterns (3). However, blood flow patterns do not aid the prediction of the distant metastases (4). By contrast, the 'soil-seed' hypothesis, as originally proposed by Paget in 1889 , states that the distribution of tumor metastases can be explained on the basis of favorable microenvironments in certain organs (5). Paget suggested that there was more to the patterns of metastasis than factors that involved blood flow (5). Data from autopsy studies may reflect metastatic lesions that, clinically, are not readily detectable and are not relevant in terms of patient management (6). The study of the metastatic behavior of malignant tumors may be complex due to the variation among individual patients. A robust understanding of metastatic patterns is of interest to clinical case management and is also significant for the field of cancer biology (7). There have been attempts to evaluate metastatic patterns, focusing largely on the use of statistical methods including cluster analysis and recursive partitioning analysis (8-10). Metastatic patterns in diseases including prostate cancer, ovarian cancer and neuroblastic tumors have been studied $(8,9)$; however, there have been few studies on the metastatic patterns in lung cancer (10-12).

In the present study, we analyzed the metastatic patterns of lung cancer cases using conditional probability, which is the probability of one event, given the occurrence of another event $(13,14)$. This statistical method is popular, but has not been used in the analysis of distant metastases. The purpose of this study was to reveal whether there was non-randomness (statistical independence) of the site in the occurrence of metastasis and whether there were specific metastatic patterns in patients with lung cancer if the non-randomness was denied. 


\section{Patients and methods}

Patients. Patients who presented with pathologically diagnosed lung cancer between January 1986 and March 2009 at the University of Tsukuba Hospital and the Tsukuba Medical Center, Japan, were identified retrospectively via computerized searches of tumor registry data. In the process of abstracting the medical records, information from diagnostic imaging, including chest CT, brain MRI or enhanced head CT, bone scan and ultrasonograpy and/or CT of the abdomen, was used to identify the location of metastatic tumors. We recorded data regarding the 5 most common metastatic sites: lung, bone, brain, liver and adrenal gland. In this study, lung metastasis was defined as separate additional nodules in a different ipsilateral lobe and additional nodules in the contralateral lung, and additional nodules in other ipsilateral lobes. However, separate nodules in the primary lobe were not included, in accordance with the seventh edition of TNM classification (15).

This study was approved by the institutional ethics committee of the University of Tsukuba Hospital.

Statistical analysis. We conducted a conditional probability analysis to test for the non-randomness of distant metastasis $(13,14)$. In brief, given the occurrence of an event A, conditional probability is the probability of another event $\mathrm{B}$ and is written $\mathrm{P}(\mathrm{B} \mid \mathrm{A})$. The probability of distant metastasis to a specific organ, for example the lung or the brain, is written $\mathrm{P}$ (lung) and $\mathrm{P}$ (brain) in this study. Under the condition of a metastatic site A, the conditional probability of distant metastasis to another specific site B (e.g,. lung and brain) is written $\mathrm{P}(\mathrm{B} \mid \mathrm{A})$. For example, the conditional probability of distant metastasis to the brain under the condition of another metastatic site in bone is written $\mathrm{P}$ (brain|bone). Events $\mathrm{A}$ and $\mathrm{B}$ are statistically independent or just independent if $\mathrm{P}(\mathrm{A} \mid \mathrm{B})=\mathrm{P}(\mathrm{B})$ [or equivalently if $\mathrm{P}(\mathrm{B} \mid \mathrm{A})=\mathrm{P}(\mathrm{A})]$.

We also used conditional probability analysis to evaluate metastatic patterns. Each of the conditional probabilities of the 5 most common metastatic sites were analyzed and revealed results for 3 of the most common metastatic sites, including $\mathrm{P}$ (lung $\mid$ (brain $\cap$ liver).

Statistical significance between the two groups was determined by the Chi-square test. The statistical analyses were performed using SAS 9.1.3 (SAS Institute Japan), R 2.8.1 software (16). $\mathrm{P}<0.05$ was considered to indicate a statistically significant result.

\section{Results}

Patient characteristics. The study group consisted of 1,994 patients (1,533 males, $76.9 \%$; 461 females, $23.1 \%$; median age, 68 years). The non-small cell lung cancer (NSCLC) group consisted of 1,674 (84.0\%) patients and the small cell lung cancer (SCLC) group had $320(16.0 \%)$ patients. Of the 1,994 patients, $839(42.1 \%)$ had distant metastases at the time of the initial diagnosis of lung cancer. The most common metastatic sites were the lung [ 368 patients, $\mathrm{P}($ lung $)=18.5 \%$ ], bone [327 patients, $\mathrm{P}($ bone $)=16.4 \%$ ], brain [248 patients, $\mathrm{P}($ brain $)=12.4 \%$ ], liver [142 patients, $\mathrm{P}($ liver $)=7.1 \%$ ] and adrenal gland [111 patients, $\mathrm{P}($ adrenal gland $)=5.6 \%$ ] (Table I)
Table I. Characteristics of 1,994 patients with lung cancer.

\begin{tabular}{lrc}
\hline Characteristics & Number & Percentage \\
\hline Age (years) & Mean, 68 & SD, 10 \\
Gender & & \\
Male & 1533 & $(76.9 \%)$ \\
Female & 461 & $(23.1 \%)$ \\
Histology & & \\
Non-small cell carcinoma & 1674 & $(84.0 \%)$ \\
Adenocarcinoma & 987 & $(49.5 \%)$ \\
Squamous cell carcinoma & 568 & $(28.5 \%)$ \\
Large cell carcinoma & 94 & $(4.7 \%)$ \\
Others & 25 & $(1.3 \%)$ \\
Small cell carcinoma & 320 & $(16.0 \%)$ \\
Lung cancer & & \\
Non-metastatic & 1155 & $(57.9 \%)$ \\
Metastatic & 839 & $(42.1 \%)$ \\
Most common metastatic sites & & \\
Lung & 368 & $(18.5 \%)$ \\
Bone & 327 & $(16.4 \%)$ \\
Brain & 248 & $(12.4 \%)$ \\
Liver & 142 & $(7.1 \%)$ \\
Adrenal gland & 111 & $(5.6 \%)$ \\
\hline
\end{tabular}

$\mathrm{SD}$, standard deviation.

Comparisons of the probability of metastasis to one organ in each histopathological type. Table II shows the comparisons of the probability of metastasis to one organ in each histopathological type of lung cancer. In patients with adenocarcinoma, $\mathrm{P}$ (lung) was the highest and $\mathrm{P}$ (lung) was higher in adenocarcinoma than in SCLC and squamous cell carcinoma. In SCLC, $\mathrm{P}$ (bone) was the highest, and it was notable that $\mathrm{P}($ liver) was higher in SCLC than in adenocarcinoma and squamous cell carcinoma. In squamous cell carcinoma, $\mathrm{P}$ (lung) was the highest; however, $\mathrm{P}$ (bone) and $\mathrm{P}$ (brain) in squamous cell carcinoma were lower than in adenocarcinoma and SCLC.

Comparison of the probability of distant metastasis and the conditional probability of metastasis to 5 of the most common metastatic sites. Table III shows the comparison of the probability of distant metastasis and the conditional probability of metastasis to five of the most common metastatic sites. With the exception of the comparisons between $\mathrm{P}$ (lung) and $\mathrm{P}$ (lung |adrenal gland) and between $\mathrm{P}($ adrenal gland) and $\mathrm{P}$ (adrenal gland $\mid$ lung), there were statistically significant differences between the probability of distant metastasis and the conditional probability of metastasis to each metastatic site. In particular, $\mathrm{P}$ (bone |liver), $\mathrm{P}$ (brain |adrenal gland), $\mathrm{P}($ liver $\mid$ bone $)$ and $\mathrm{P}$ (liver|adrenal gland), and $\mathrm{P}$ (adrenal gland|liver) and $\mathrm{P}$ (adrenal gland $\mid$ brain) were 3 times higher than $\mathrm{P}($ bone $)$, $\mathrm{P}$ (brain), $\mathrm{P}($ liver) and $\mathrm{P}$ (adrenal gland), respectively.

Probability of metastasis confined to one organ. Table IV shows the probability of metastasis confined to only one organ. 
Table II. Comparison of the probability of metastasis to one organ in histopathological types of lung cancer.

$\mathrm{P}(\mathrm{A})(95 \% \mathrm{CI})$

\begin{tabular}{lccc}
\cline { 2 - 3 } Organ A & Adenocarcinoma $(\mathrm{n}=987)$ & Small cell carcinoma $(\mathrm{n}=320)$ & Squamous cell carcinoma $(\mathrm{n}=568)$ \\
\hline Lung & $23.3(20.7-25.9)$ & $13.4(9.7-17.2)$ & $13.7(11.6-15.9)$ \\
Bone & $20.2(17.7-22.7)$ & $20.9(16.5-25.4)$ & $9.0(7.2-10.8)$ \\
Brain & $16.0(13.7-18.3)$ & $16.6(12.5-20.6)$ & $4.8(3.4-6.1)$ \\
Liver & $6.6(5.0-8.1)$ & $17.8(13.6-22.0)$ & $3.3(2.2-4.5)$ \\
Adrenal gland & $6.8(5.2-8.4)$ & $7.2(4.4-10.0)$ & $2.6(1.6-3.6)$ \\
\hline
\end{tabular}

CI, confidence interval.

Table III. Comparison of probability of distant metastasis and conditional probability of additional distant metastasis to the 5 most common metastatic sites.

\begin{tabular}{|c|c|c|c|c|}
\hline \multirow{2}{*}{$\begin{array}{l}\text { Probability }(95 \% \mathrm{CI}) \\
\mathrm{P}(\mathrm{Lu})\end{array}$} & \multicolumn{4}{|c|}{ Conditional probability } \\
\hline & $\mathrm{P}(\mathrm{Lu} \mid \mathrm{Bo})$ & $\mathrm{P}(\mathrm{Lu} \mid \mathrm{Br})$ & $\mathrm{P}(\mathrm{Lu} \mid \mathrm{Li})$ & $\mathrm{P}(\mathrm{Lu} \mid \mathrm{Ad})$ \\
\hline $18.5(16.8-20.2)$ & $30.0(98 / 327)$ & $26.6(66 / 248)$ & $29.6(42 / 142)$ & $26.1(29 / 111)$ \\
\hline p-value & $<0.01$ & $<0.01$ & $<0.01$ & 0.08 \\
\hline $\mathrm{P}(\mathrm{Bo})$ & $\mathrm{P}(\mathrm{Bo} \mid \mathrm{Lu})$ & $\mathrm{P}(\mathrm{Bo} \mid \mathrm{Br})$ & $\mathrm{P}(\mathrm{Bo} \mid \mathrm{Li})$ & $\mathrm{P}(\mathrm{Bo} \mid \mathrm{Ad})$ \\
\hline $16.4(14.8-18.0)$ & $26.6(98 / 368)$ & $38.3(95 / 248)$ & $54.2(77 / 142)$ & $42.3(47 / 111)$ \\
\hline p-value & $<0.01$ & $<0.01$ & $<0.01$ & $<0.01$ \\
\hline $\mathrm{P}(\mathrm{Br})$ & $\mathrm{P}(\mathrm{Br} \mid \mathrm{Lu})$ & $\mathrm{P}(\mathrm{Br} \mid \mathrm{Bo})$ & $\mathrm{P}(\mathrm{Br} \mid \mathrm{Li})$ & $\mathrm{P}(\mathrm{Br} \mid \mathrm{Ad})$ \\
\hline $12.4(11.1-13.9)$ & $17.9(66 / 368)$ & $29.1(95 / 327)$ & $27.5(39 / 142)$ & $40.5(45 / 111)$ \\
\hline $\mathrm{p}$-value & 0.013 & $<0.01$ & $<0.01$ & $<0.01$ \\
\hline $\mathrm{P}(\mathrm{Li})$ & $\mathrm{P}(\mathrm{Li} \mid \mathrm{Lu})$ & $\mathrm{P}(\mathrm{Li} \mid \mathrm{Br})$ & $\mathrm{P}(\mathrm{Li} \mid \mathrm{Bo})$ & $\mathrm{P}(\mathrm{Li} \mid \mathrm{Ad})$ \\
\hline $7.1(6.0-8.3)$ & $11.4(42 / 368)$ & $15.7(39 / 248)$ & $23.5(77 / 327)$ & $25.2(28 / 111)$ \\
\hline $\mathrm{p}$-value & 0.014 & $<0.01$ & $<0.01$ & $<0.01$ \\
\hline $\mathrm{P}(\mathrm{Ad})$ & $\mathrm{P}(\mathrm{Ad} \mid \mathrm{Lu})$ & $\mathrm{P}(\mathrm{Ad} \mid \mathrm{Bo})$ & $\mathrm{P}(\mathrm{Ad} \mid \mathrm{Li})$ & $\mathrm{P}(\mathrm{Ad} \mid \mathrm{Br})$ \\
\hline $5.6(4.6-6.6)$ & $7.9(29 / 368)$ & $14.4(47 / 327)$ & $19.7(28 / 142)$ & $18.1(45 / 248)$ \\
\hline $\mathrm{p}$-value & 0.124 & $<0.01$ & $<0.01$ & $<0.01$ \\
\hline
\end{tabular}

Lu, lung; Bo, bone; Br, brain; Li, liver; Ad, adrenal gland; CI, confidence interval. P-value is the result of the test of equality between the probability in the first column from the left and each of the successive conditional probabilities from the second to fifth columns using the Chi-square test. The fraction beside probability $\mathrm{P}(\mathrm{A})$ in the first column from the left shows the estimation of its proportion by the division of the number of patients with metastasis to organ $\mathrm{A}$ by total patients, and the fractions beside conditional probability $\mathrm{P}(\mathrm{BI} \mathrm{A})$ show the estimation of the probability of metastasis to organ B conditioned on the metastasis to organ A patients, $\mathrm{P}(\mathrm{A} \mid \mathrm{B}) / \mathrm{P}(\mathrm{A})$.

Of the 368 patients with lung metastasis, 199 (54.1\%) had metastasis confined to the lung. Similarly, 110 of 327 patients $(33.6 \%)$ with bone metastasis and 89 of 248 patients $(35.9 \%)$ with brain metastasis had the metastasis confined to the metastatic organ concerned. However, 28 of 142 patients $(19.7 \%)$ with liver metastasis and 19 of 111 patients (17.1\%) with adrenal gland metastasis had metastases in organs other than the liver and adrenal gland, respectively. There were statistically significant differences in the ratio between the two groups of organs $(p=0.001)$. Table IV also shows the probability of metastasis confined to only two organs. Lung and bone $[\mathrm{P}($ confined to lung and brain $)=37.8 \%]$ and brain and bone
$[\mathrm{P}($ confined to brain and bone $)=32.6 \%]$ had the highest probability of metastasis confined to only those two organs.

Progression of metastasis from bone to a second and third organ. Table $\mathrm{V}$ shows the conditional probabilities $\mathrm{P}(\mathrm{B} \mid \mathrm{A})$ and $\mathrm{P}(\mathrm{C}|\mathrm{B}| \mathrm{A})$ and the percentage of patients who had metastasis confined to only the three organs concerned, when bone was organ A. Table V shows the theoretical progression of metastasis from bone to a second and then to a third organ. The conditional probabilities of metastasis to the lung, brain, liver and adrenal gland if there was already bone metastasis were 30.0, $29.1,23.5$ and $14.4 \%$, respectively. An additional conditional 
Table IV. Probability of metastasis confined to only one organ and confined to only two organs.

\begin{tabular}{|c|c|c|c|c|c|}
\hline Organ A & No. of patients ${ }^{\mathrm{a}}$ & $\begin{array}{l}\mathrm{P}(\text { confined to } \mathrm{A}) \\
(95 \% \mathrm{CI})\end{array}$ & Organ B & No. of patients ${ }^{b}$ & $\begin{array}{l}\mathrm{P}(\text { confined to } \mathrm{A} \text { and } \mathrm{B}) \\
(95 \% \mathrm{CI})\end{array}$ \\
\hline \multirow[t]{4}{*}{ Lung } & \multirow[t]{4}{*}{$199 / 368$} & \multirow[t]{4}{*}{$54.1(49.0-59.2)$} & Bone & $37 / 98$ & $37.8(28.2-47.4)$ \\
\hline & & & Brain & $16 / 66$ & $24.2(13.9-34.6)$ \\
\hline & & & Liver & $10 / 42$ & $23.8(10.9-36.7)$ \\
\hline & & & Adrenal gland & $5 / 29$ & $17.2(3.5-31.0)$ \\
\hline \multirow[t]{4}{*}{ Bone } & \multirow[t]{4}{*}{$110 / 327$} & \multirow[t]{4}{*}{$33.6(28.5-38.8)$} & Lung & $37 / 98$ & $37.8(28.2-47.4)$ \\
\hline & & & Brain & $31 / 95$ & $32.6(23.2-42.1)$ \\
\hline & & & Liver & $18 / 77$ & $23.4(13.9-32.8)$ \\
\hline & & & Adrenal gland & $11 / 47$ & $23.4(11.3-35.5)$ \\
\hline \multirow[t]{4}{*}{ Brain } & \multirow[t]{4}{*}{$89 / 248$} & \multirow[t]{4}{*}{$35.9(29.9-41.9)$} & Lung & $16 / 66$ & $24.2(13.9-34.6)$ \\
\hline & & & Bone & $31 / 95$ & $32.6(23.2-42.1)$ \\
\hline & & & Liver & $2 / 39$ & $5.1(0-12.1)$ \\
\hline & & & Adrenal gland & $12 / 45$ & $26.7(13.7-39.6)$ \\
\hline \multirow[t]{4}{*}{ Liver } & \multirow[t]{4}{*}{$28 / 142$} & \multirow[t]{4}{*}{$19.7(13.2-26.3)$} & Lung & $10 / 42$ & $23.8(10.9-36.7)$ \\
\hline & & & Bone & $18 / 77$ & $23.4(13.9-32.8)$ \\
\hline & & & Brain & 2/39 & $5.1(0-12.1)$ \\
\hline & & & Adrenal gland & $3 / 28$ & $10.7(0-22.2)$ \\
\hline \multirow[t]{4}{*}{ Adrenal gland } & \multirow[t]{4}{*}{$19 / 111$} & \multirow[t]{4}{*}{$17.1(10.1-24.1)$} & Lung & $5 / 29$ & $7.2(3.5-31.0)$ \\
\hline & & & Bone & $11 / 47$ & $23.4(11.3-35.5)$ \\
\hline & & & Brain & $12 / 45$ & $26.7(13.7-39.6)$ \\
\hline & & & Liver & $3 / 28$ & $10.7(0-22.2)$ \\
\hline
\end{tabular}

${ }^{a}$ Number of patients with metastasis confined to organ A only/number of patients with metastasis to organ A. ${ }^{b}$ Number of patients with metastasis confined to organs A and B only/number of patients with metastasis to organs A and B. CI, confidence interval.

Table V. Conditional probabilities $\mathrm{P}(\mathrm{B} \mid \mathrm{A})$ and $\mathrm{P}(\mathrm{C}|\mathrm{B}| \mathrm{A})$ of 1,994 lung cancer patients with metastasis confined to the organs concerned only, when bone was organ A.

\begin{tabular}{|c|c|c|c|c|c|}
\hline Organ B & $\begin{array}{c}\mathrm{P}(\mathrm{B} \mid \mathrm{A}) \\
(\%)\end{array}$ & $\begin{array}{l}\text { Metastasis } \\
\text { confined to only } \\
\text { A and B (\%) }\end{array}$ & Organ C & $\begin{array}{c}\mathrm{P}(\mathrm{C}|\mathrm{B}| \mathrm{A}) \\
(\%)\end{array}$ & $\begin{array}{c}\text { Metastasis } \\
\text { confined to only } \\
\text { A, B and C (\%) }\end{array}$ \\
\hline \multirow[t]{3}{*}{ Lung } & \multirow[t]{3}{*}{30.0} & \multirow[t]{3}{*}{37.8} & Brain & 35.7 & 57.1 \\
\hline & & & Liver & 25.5 & 36.0 \\
\hline & & & Adrenal gland & 10.2 & 10.0 \\
\hline \multirow[t]{3}{*}{ Brain } & \multirow[t]{3}{*}{29.1} & \multirow[t]{3}{*}{32.6} & Lung & 36.8 & 57.1 \\
\hline & & & Liver & 29.5 & 39.3 \\
\hline & & & Adrenal gland & 18.9 & 38.9 \\
\hline \multirow[t]{3}{*}{ Liver } & \multirow[t]{3}{*}{23.5} & \multirow[t]{3}{*}{23.4} & Lung & 32.5 & 36.0 \\
\hline & & & Brain & 36.4 & 39.3 \\
\hline & & & Adrenal gland & 24.7 & 26.3 \\
\hline \multirow[t]{3}{*}{ Adrenal gland } & \multirow[t]{3}{*}{14.4} & \multirow[t]{3}{*}{23.4} & Lung & 21.3 & 10.0 \\
\hline & & & Brain & 38.3 & 38.9 \\
\hline & & & Liver & 40.4 & 26.3 \\
\hline
\end{tabular}

probability was observed if there were metastases to the bone and two other organs. We also performed the same analyses with the lung and the brain as organ A (data not shown). These results revealed that $\mathrm{P}(\mathrm{B} \mid \mathrm{A})$ and $\mathrm{P}(\mathrm{C}|\mathrm{B}| \mathrm{A})$ were different when organ A was different. This suggests that there were certain specific patterns of distant metastasis in lung cancer patients. 


\section{Discussion}

Distant metastasis is almost always encountered in the course of lung cancer. Initial staging evaluations have determined that $40-60 \%$ of patients present with metastatic disease $(17,18)$. The most common sites of metastasis encountered in pretreatment evaluations are the lung, bone, brain, liver and adrenal gland (19-22). Increased knowledge of what determines the metastatic potential of lung cancer may be used to aid selection of the most appropriate treatment. Clinical and histological variables are not sufficient to fully explain all the differences in metastatic potential and subsequent progression and, accordingly, increased information on the biological characteristics of the tumors is also needed. There are few studies in the literature that provide detailed data on the metastatic patterns of lung cancers (10-12). There have been attempts to evaluate metastatic patterns, focusing largely on the use of biological methods $(7,23)$.

Using conditional probability analysis, which is one of the most common mathematical methods but a novel analytical method in the area of clinical study, we evaluated the metastatic patterns of lung cancer and found three significant points. Firstly, we compared $\mathrm{P}(\mathrm{B} \mid \mathrm{A})$ with $\mathrm{P}(\mathrm{B})$ and found that there were statistically significant differences between them in the 5 metastatic organs, with the exception of the comparisons between $\mathrm{P}$ (lung) and $\mathrm{P}$ (lung |adrenal gland) and between $\mathrm{P}$ (adrenal gland) and $\mathrm{P}($ adrenal gland $\mid$ lung). This finding indicated that distant metastasis occurred non-randomly. The exceptions may be due to the small number of cases of adrenal gland metastasis. At presentation, metastasis appeared not to affect distant organs at random in most of the lung cancer patients, although dissemination to the whole body was occasionally observed at the time of autopsy. Secondly, there were certain specific patterns of distant metastasis in lung cancer patients. The exact analysis of the metastatic patterns in lung cancer may contribute to our understanding of the natural history of this malignant tumor. Additionally, knowledge of the natural history of lung cancer may aid the prediction of survival, establishment of follow-up schedules and guidance of treatment. An improved understanding of the factors affecting metastasis may lead to new insights into the requirements for tumor growth and direct the development of new diagnostic approaches and therapeutic agents. Thirdly, the present study revealed that the probability of metastasis confined to one or two organs varied according to each organ. The probability that metastasis was confined to one organ was high in the lungs $(54.1 \%)$, bone (33.6\%) and brain (35.9\%). However, the probability of metastasis was low in the liver (19.7\%) and adrenal gland (17.1\%). Additionally, lung and bone (37.8\%) and brain and bone $(32.6 \%)$ were two organs that had the highest probability of metastasis confined to only those two organs.

Although this study has produced some novel information, there were certain limitations. Firstly, there was no pathological confirmation of distant metastases and determining the location of distant metastases depended on the imaging diagnostic methods. Secondly, although our study included the consecutive patients with pathologically proven lung cancer, our patient base did not reflect the overall patient population in the community. Thirdly, this was a retrospective analysis of only metastatic data from the time of the initial diagnosis of lung cancer and there was no evaluation of metastases which developed during the clinical course of the disease. It was thought that the results may be different if we considered data of the metastases that developed during their clinical courses. However, the type of diagnostic imaging techniques carried out and the intervals at which they were performed may become a problem. Lastly, the accumulation period of this study was long, therefore lung cancer patients from the 1980s were included. As there has been progress in diagnostic imaging techniques since this period, the precision of the techniques may be different among patients from this period and this may influence the results. Therefore, we assume that knowledge of metastatic patterns may be updated further in the future by the development of new imaging techniques, for example fluoro-2deoxy-d-glucose positron emission tomography.

Distant metastasis may occur non-randomly and there were certain specific patterns of distant metastasis in lung cancer patients. The patterns of metastasis, which were revealed by statistical analysis, suggest that there is a mechanism which involves more than the 'mechanical theory' (3) and 'soil-seed hypothesis' (5) in the progression of distant metastases from a biological perspective. The accumulation of knowledge of specific patterns of metastasis may aid the approach to individual treatment.

\section{References}

1. Brunelli A, Charloux A, Bolliger CT, et al: ERS/ESTS clinical guidelines on fitness for radical therapy in lung cancer patients (surgery and chemo-radiotherapy). Eur Respir J 34: 17-41, 2009.

2. Viadana E and Au K-L: Patterns of metastases in adenocarcinoma of man. J Med 6: 1-14, 1975.

3. Ewing J (ed): Metastasis. In: Neoplastic Diseases: A Treatise on Tumours. 3rd edition. W.B. Saunders, Philadelphia, pp76-88, 1928.

4. Woodhouse EC, Chuaqui RF and Liotta LA: General mechanisms of metastasis. Cancer 80 (Suppl 8): 1529-1537, 1997.

5. Paget S: The distribution of secondary growths in cancer of the breast. Lancet 133: 571-573, 1889.

6. de Pangher Manzini V, Revignas MG and Brollo A: Diagnosis of malignant tumor: comparison between clinical and autopsy diagnoses. Hum Pathol 26: 280-283, 1995.

7. Riethdorf S, Wikman H and Pantel K: Review: Biological relevance of disseminated tumor cells in cancer patients. Int $\mathrm{J}$ Cancer 123: 1991-2006, 2008.

8. de la Monte SM, Moore GW and Hutchins GM: Nonrandom distribution of metastases in neuroblastic tumors. Cancer 52: 915-925, 1983.

9. de la Monte SM, Moore GW and Hutchins GM: Metastatic behavior of prostate cancer. Cluster analysis of patterns with respect to estrogen treatment. Cancer 58: 985-993, 1986.

10. Hess KR, Varadhachary GR, Taylor SH, et al: Metastatic patterns in adenocarcinoma. Cancer 106: 1624-1633, 2006.

11. Elliott JA, Osterlind K, Hirsch FR, et al: Metastatic patterns in small-cell lung cancer: correlation of autopsy findings with clinical parameters in 537 patients. J Clin Oncol 5: 246-54, 1987.

12. Nomori H, Matsuno Y, Noguchi M, et al: Adenocarcinoma of the lung with selective metastasis to the lung: clinical, histologic and DNA-cytofluorometric analyses. Jpn J Cancer Res 83: 93-100, 1992.

13. Hand DJ: Statistical methods in diagnosis. Stat Methods Med Res 1: 49-67, 1992.

14. Davis FG, McCarthy BJ, Freels S, et al: The conditional probability of survival of patients with primary malignant brain tumors: surveillance, epidemiology, and end results (SEER) data. Cancer 85: 485-491, 1999.

15. Lababede O, Meziane M and Rice T: Seventh edition of the cancer staging manual and stage grouping of lung cancer: quick reference chart and diagrams. Chest 139: 183-189, 2011.

16. Ihaka R and Gentleman R: A language for data analysis and graphics. J Comp Graph Stat 5: 299-314, 1996. 
17. Satoh H, Kurishima K, Nakamura R, et al: Lung cancer in patients aged 80 years and over. Lung Cancer 65: 112-118, 2009.

18. Kobrinsky NL, Klug MG, Hokanson PJ, et al: Impact of smoking on cancer stage at diagnosis. J Clin Oncol 21: 907-913, 2003.

19. Satoh H, Ishikawa H, Kamma H, et al: Serum sialyl Lewis $X-1$ antigen levels in non-small cell lung cancer: correlation with distant metastasis and survival. Clin Cancer Res 3: 495-499, 1997.

20. Olak J: Surgical strategies for metastatic lung cancer. Surg Oncol Clin N Am 8: 245-257, 1999.
21. Pfannschmidt J and Dienemann H: Surgical treatment of oligometastatic non-small cell lung cancer. Lung Cancer 69: 251-258, 2010.

22. Ishikawa H, Satoh H, Kurishima K, et al: Lung cancer with synchronous brain and bone metastasis. Clin Oncol (R Coll Radiol) 12: 136-137, 2000.

23. Pantel K, Alix-Panabières $C$ and Riethdorf S: Cancer micrometastases. Nat Rev Clin Oncol 6: 339-351, 2009. 